\title{
Endoscopic Endonasal Resection of Tuberculum Sellae Meningioma with Utilization of Indocyanine Green
}

\author{
Mostafa Shahein $^{1}$ Alaa S. Montaser ${ }^{1,2}$ Alexandre B. Todeschini ${ }^{1}$ Juan M. Revuelta Barbero ${ }^{1}$ \\ Bradley A. Otto ${ }^{1,3}$ Ricardo L. Carrau ${ }^{1,3}$ Daniel M. Prevedello ${ }^{1,3}$
}

\footnotetext{
${ }^{1}$ Department of Neurological Surgery, Wexner Medical Center, The Ohio State University, Columbus, Ohio, United States

2 Department of Neurological Surgery, Ain Shams University Faculty of Medicine, Cairo, Egypt

${ }^{3}$ Department of Otolaryngology-Head and Neck Surgery, Wexner Medical

Center at The Ohio State University, Columbus, Ohio, United States
}

\begin{abstract}
Address for correspondence Daniel M. Prevedello, MD, Department of Neurological Surgery, Wexner Medical Center at The Ohio State University, N-1049 Doan Hall, 410 West 10th Avenue, Columbus, $\mathrm{OH}$ 43210, United States (e-mail: daniel.prevedello@osumc.edu).
\end{abstract}

J Neurol Surg B 2018;79(suppl S3):S269-S270.

\begin{abstract}
Keywords

- endoscopic endonasal

- tuberculum sellae meningioma

- indocyanine green

- ICG

We present the case of a 67-year-old female with an incidental finding of a left-sided tuberculum sellae meningioma on a brain magnetic resonance imaging (MRI) for an unrelated complaint. Formal visual field testing showed a small defect in the inferior nasal and temporal fields of the left eye, compatible with mass effect on the optic nerve by the tumor.

An endoscopic endonasal transtuberculum approach with decompression of the left optic nerve was performed using a standard binostril four-hand technique, with the patient positioned supine with the head turned to the right side and tilted to the left, fixed in a three-pin head clamp, under imaging guidance. After exposure, we drilled the tuberculum sellae and the floor of the sella and after opening the dura, the tumor and optic nerve came into view. The tumor was completely removed and we confirmed the patency of all perforating vessels using indocyanine green. Reconstruction was done in a multilayered fashion, using collagen matrix and a nasoseptal flap.

Patient had an uneventful postoperative stay and was discharged on postoperative day 3 , neurologically stable with no new hormonal deficits. Pathology report confirmed a WHO Grade I meningioma with $K_{\mathrm{i}}-67$ of $1 \%$ and 3-month postoperative MRI confirmed a gross total resection and visual fields exam showed a complete recovery. The link to the video can be found at: https://youtu.be/zRmt2alvX5c.
\end{abstract}

Conflict of Interest

None.

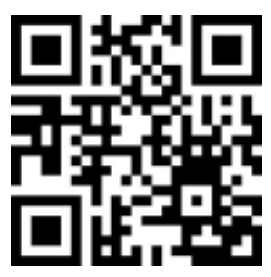

www.thieme.com/skullbasevideos

www.thieme.com/jnlsbvideos

received

October 24, 2017

accepted

December 13, 2017

published online

February 14, 2018
DOI https://doi.org/

10.1055/s-0038-1625939.

ISSN 2193-6331. (c) 2018 Georg Thieme Verlag KG Stuttgart . New York
License terms

(ㄷ) (i) $\ominus$ (\$) 


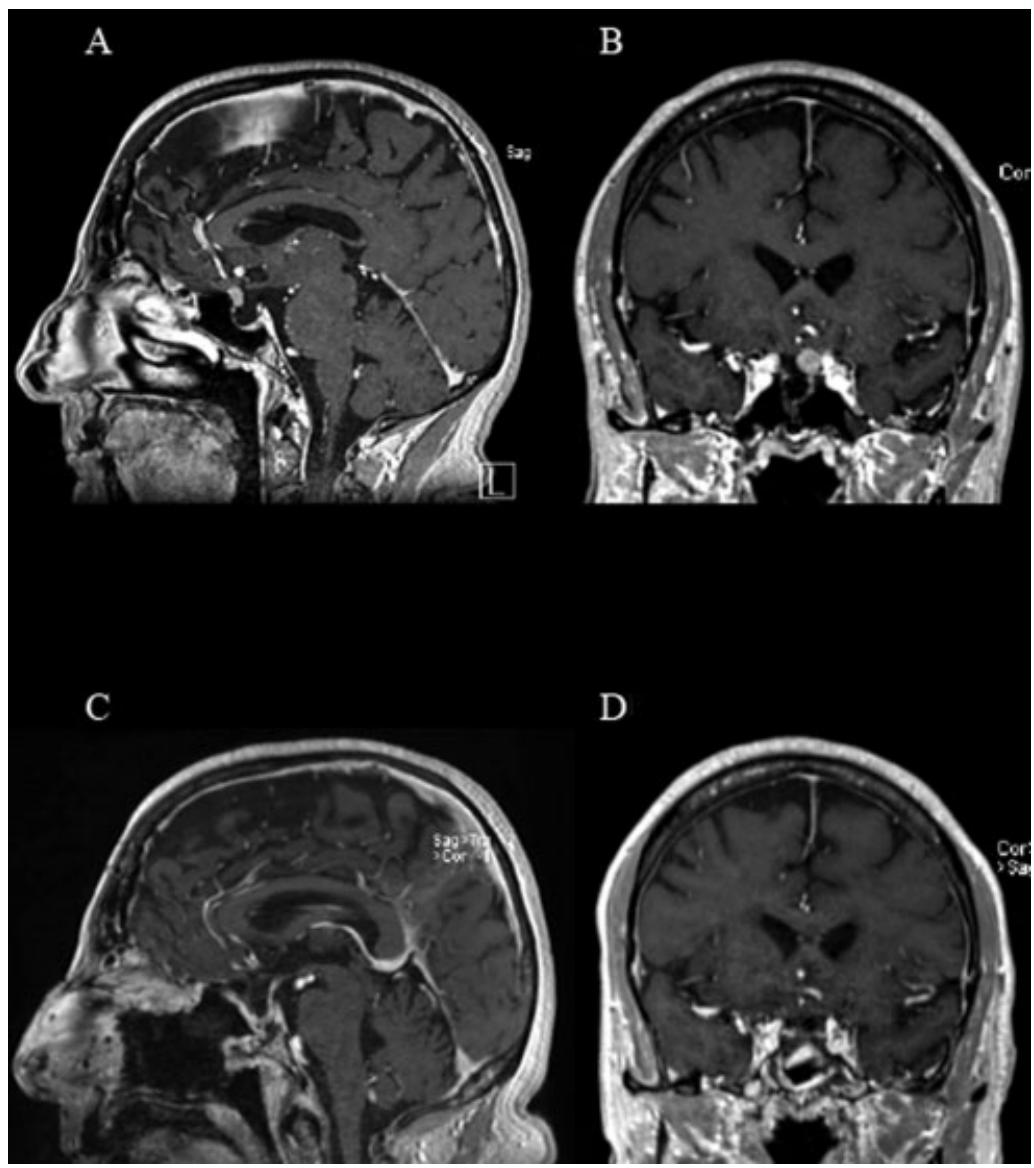

Fig. 1 Preoperative brain magnetic resonance imaging (MRI) sagittal (A) and coronal (B) views with gadolinium contrast showing tuberculum sellae meningioma abutting the left internal carotid artery, displacing the left optic nerve superiorly. Postoperative brain MRI sagittal (C) and coronal (D) views with gadolinium contrast showing complete tumor resection.

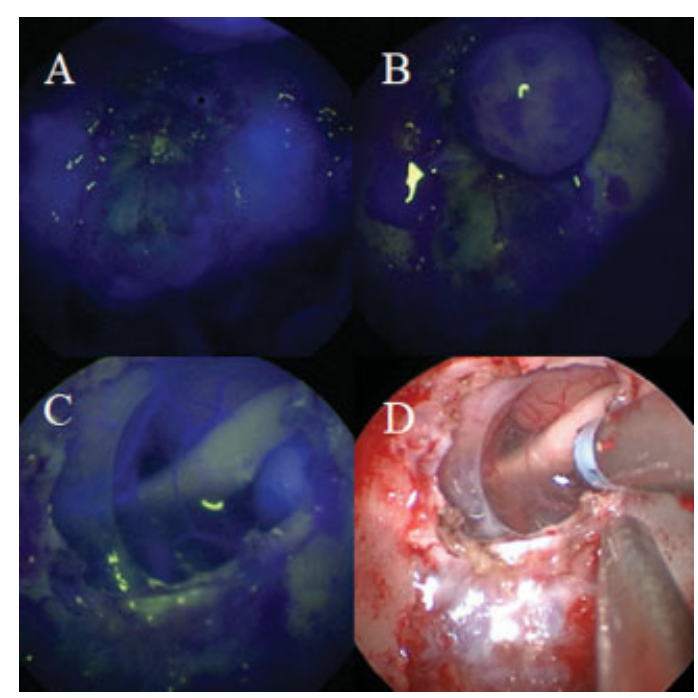

Fig. 2 Intraoperative view after first indocyanine green (ICG) injection (A) showing both internal carotid arteries indicates area of the dura attachment still vascularized and coagulated later during surgery. The tumor is demonstrating enhancement (B) following resection of the dural attachment. Intraoperative view after second ICG injection (C) showing parts of the tumor still enhancing at the periphery of the excised dura on the left side indicating small residual. Note the enhancement of the superior hypophyseal artery and internal carotid artery on the left side, indicating their patency. Cauterization of the residual tumor (D) followed by completion of resection. 